Viso - Cadernos de estética aplicada Revista eletrônica de estética

ISSN 1981-4062

$N^{\circ} 12$, jul-dez/2012

http://www.revistaviso.com.br/
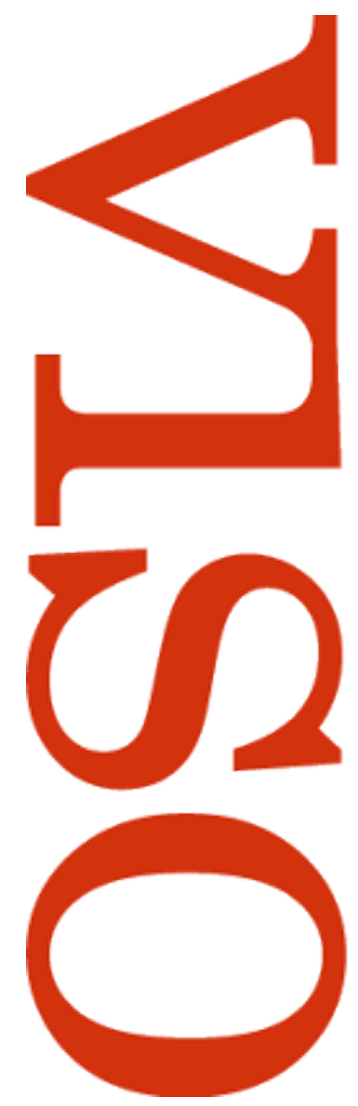

\title{
Desejo e pulsão em Psicose, de Hitchcock
} Fernando Ribeiro 


\section{RESUMO}

Desejo e pulsão em Psicose, de Hitchcock

Dialogando com as análises de Zizek acerca de Psicose, de Hitchcock, esse artigo põe em relevo três momentos do filme claramente delimitáveis quanto a forma e o conteúdo. A primeira parte, "neurótica", na qual os personagens giram em torno do objeto perdido de desejo; a segunda, "psicótica", na qual a perspectiva assumida é a do silêncio "excessivo" da pulsão; a terceira parte, "analítica", onde três concepções da interpretação são erigidas: a do senso comum, a do analista como "mestre da significação", e por último, mas não menos importante, a da "clínica do real", quando o próprio espectador é interpelado pela pulsão de morte.

Palavras-chave: Hitchcock - Lacan - Zizek - psicanálise - pulsão - interpretação

\section{ABSTRACT}

\section{Desire and drive in Hitchcock's Psycho}

In dialogue with the zizekian analysis of Hitchcock's Psycho, this paper puts in relief three moments of the film clearly distinguishable by its form and content. The first part, "neurotic", in which the characters revolve around the lost object of desire; the second, "psychotic", where the perspective taken is that of the "excessive" silence of the drive; the third one, the "analytic" part, where three conceptions of interpretation are built: that of the common sense, that of the analyst like "master of signification", and last but not least, that of "real's clinic", when the spectator himself is interpellated by the death drive.

Keywords: Hitchcock - Lacan - Zizek - psychoanalysis - drive - interpretation 
RIBEIRO, F. "Desejo e pulsão em Psicose, de Hitchcock". In: Viso: Cadernos de estética aplicada, v. VI, n. 12 (jul-dez/2012), pp. 116-127.

DOI: $10.22409 / 1981-4062 / v 12 i / 145$

Aprovado: 11.03.2013. Publicado: 13.07.2013.

(C) 2013 Fernando Ribeiro. Esse documento é distribuído nos termos da licença Creative Commons Atribuição-NãoComercial 4.0 Internacional (CC-BY-NC), que permite, exceto para fins comerciais, copiar e redistribuir o material em qualquer formato ou meio, bem como remixá-lo, transformá-lo ou criar a partir dele, desde que seja dado o devido crédito e indicada a licença sob a qual ele foi originalmente publicado.

Licença: http://creativecommons.org/licenses/by-nc/4.0/deed.pt_BR

Accepted: 11.03.2013. Published: 13.07.2013.

(C) 2013 Fernando Ribeiro. This document is distributed under the terms of a Creative Commons Attribution-NonCommercial 4.0 International license (CC-BY-NC) which allows, except for commercial purposes, to copy and redistribute the material in any medium or format and to remix, transform, and build upon the material, provided the original work is properly cited and states its license.

License: http://creativecommons.org/licenses/by-nc/4.0/ 


\section{Introdução}

O inconsciente em psicanálise tem o estatuto de uma hipótese formal. Isto é, não deve ser confundido com uma entidade natural, nem suprassensível. A relação entre sujeito e objeto de desejo inconsciente pode ser analisada a partir de componentes e operações abstraídas da clínica, sem se levar em conta qualquer metafísica humanista, ou evocar qualquer "potência" ontológica. Tampouco se trata da busca de um significado oculto sob a cena embaralhada do sonho: na verdade, trata-se de uma dialética não totalizante, que subverte a relação filosófica tradicional entre aparência e essência, ou significante e significado. Nossa análise da relação entre desejo e pulsão em Psicose, de Hitchcock, que dialoga com Zizek, adota tal perspectiva critico-clínica.

O pano de fundo de Psicose, de Alfred Hitchcock, é o cotidiano cinzento de pessoas ordinárias, confinadas em esperanças e medos miseráveis (solidão, falta de dinheiro, medo da polícia, esforços desesperados para obter uma parcela mínima de felicidade), confrontado com a vertente noturna da psicose: o crime patológico. Não se trata de doença biológica, mas de uma patologia das identificações. ${ }^{1}$

\section{Resumo do filme}

Phoenix, Arizona, Dezembro, duas e quarenta e três da tarde. Através de uma janela, adentramos num quarto de hotel. Após um prelúdio erótico, trava-se uma conversa tensa entre a secretária Marion Crane e seu namorado, que enfrenta problemas com a pensão da ex-mulher. Os dois se despedem e ela retorna para o escritório. É uma tarde quente de sexta-feira e ela pede licença ao patrão para sair mais cedo, levando consigo o pacote de dinheiro - 40 mil dólares - a ela confiado para depositar no banco. Trata-se de uma quantia destinada à compra da casa da filha do dono da firma. Este aparecera por lá bêbado, dirigindo a Marion palavras em tom licencioso. Mais tarde, em seu quarto, ela reflete e, confusa, movida por um impulso de momento, ela resolve dar um desfalque na imobiliária onde trabalha. Certa de que seu crime só seria percebido após o final de semana, a mocinha sai dirigindo sem destino preciso. Na noite tempestuosa e relampejante, que reflete o estado psíquico da personagem, Marion se angustia com pensamentos do tipo: "O que os outros a essa hora estarão pensando de mim?", num monólogo interior que funciona ao mesmo tempo como relato provável das ações a transcorrerem no extra-campo. $\mathrm{O}$ dia amanhece com Marion adormecida no carro à beira da estrada. Depois de ser abordada por um policial e trocar de veículo, cansada, numa noite chuvosa, ela vai parar no Motel Bates, um lugar decadente, que quase fechou suas portas após o desvio da auto-estrada. Lá, é recepcionada por um simpático mas estranho rapaz, Norman Bates, um tímido, dominado pela mãe. Após uma conversa e 
um rápido sanduíche, acontece o inesperado: Marion é brutalmente esfaqueada enquanto toma banho, numa das cenas mais famosas de toda a história do cinema. Neste momento, o eixo da narrativa se desloca para a perspectiva de Norman, durante um trecho silencioso (a pulsão é silenciosa) do filme, mais de dez minutos, desde a lavagem do banheiro até o momento em que o carro com a vítima, sua mala e o dinheiro afunda no pântano, não sem antes um pequeno suspense. Segue-se desde então a parte do desvendamento do sumiço de Marion. Primeiro com o detetive Arbogast, que também acaba morto pela suposta mãe; depois pela irmã Lylah com o namorado de Marion, Sam. Estes, terminam descobrindo que o esfaqueador é o próprio Norman, travestido. Um psiquiatra explica que ele, órfão de pai, adotara uma dupla personalidade para não assumir a responsabilidade pela morte da mãe, tendo a assassinado quando esta passou a se relacionar com outro homem. O crime não fora por dinheiro, portanto, mas por paixão. A parte mãe de Norman era agressiva com as mulheres que atraíam a outra parte. Nos últimos dois segundos, a face de Norman agasalhado sob um cobertor na sala da delegacia se funde com a da caveira da mãe, que nos encara sarcasticamente com um sorriso maligno e cúmplice.

\section{Análise}

O filme é dividido em três partes bem delimitadas. Cada uma das duas primeiras transcorre segundo uma temporalidade própria, que designaremos, seguindo a pista de Zizek, ora como temporalidade do desejo, ora como temporalidade da pulsão; e por fim, na terceira parte, a da decifração do crime, trataremos das várias formas de "interpretação" apresentadas, desde aquela (imaginária) do senso comum, passando pela do psiquiatra como "mestre da significação" (simbólica) até a "clínica do real" de Lacan, quando nos deparamos com o olhar vazado da caveira.

Primeira parte. Música de ritmo agressivo, como facadas. Dos créditos ao assassinato de Marion na banheira se expressa a lógica "neurótica" do desejo, com seu caráter deslizante na busca incansável do objeto de satisfação, que promoveria, enfim, a "relação sexual". Mas através de que artifícios se "filma o desejo"? A solução de Hitchcock foi a topologia da entrevisão por uma fenda. De asída, o movimento da câmera em direção à janela nos engaja numa atmosfera ambígua "fora da lei", como o que se passa num quarto de motel, em pleno "horário do almoço". Temos também a bolsa entreaberta que metaforiza o objeto do desejo como algo sempre "entrevisto", e portanto faltoso. Os personagens giram em torno dos 40 mil dólares surrupiados pela secretária de um velho (pai) gozador, amigo do dono da imobiliária onde a mocinha, com quem nos identificamos imediatamente, trabalha. Para Zizek, o momento da troca de sutiã indica que ela já decidiu, mas me pergunto se a culpa gerada pelo olhar do gerente que a interpela no sinal de trânsito não seria o momento em que o crime é de fato subjetivado performativa (e retroativa) mente. Marion pode bem ter pensado nesse instante: "Ora, se 
o Grande Outro me tem desde então como culpada, por que não cometer de vez o crime, a fim de justificá-lo?" Para Freud, o sofrimento engendrado pelo supereu se acha desvinculado das ações e dos fatos "objetivos", sendo uma expressão pura da pulsão de morte, de uma agressividade autoinfligida, original e autossubsistente. Nesse sentido, pode-se dizer que a culpa antecede o crime. A culpa neurótica da protagonista se encena também pela opacificação do olhar do guarda sob os óculos escuros Ray-ban. Isso sublinha o aspecto "desencarnado" do supereu, que invade a janela do carro, perdendose então a própria neutralidade da câmera. A multiplicação dessa perspectiva culpabilizante, quando Marion deixa a loja de carros usados, só faz reforçar o aspecto sufocante do supereu, que resulta tão mais exigente quanto mais é atendido em suas exigências imperativas.

Enquanto a jovem dirige, presa de forte culpabilidade, somos transportados do contexto da cidade moderna para um ambiente rural, onde se situa o Motel Bates. $O$ encontro entre Norman e Marion sugere uma simpatia imediata e, mesmo atarantada pela fuga, ela se apresenta como mulher diante dele, que a cobiça um tanto desajeitado. Ele sai para preparar um sanduíche. Após ouvir, numa voz pairando no ar, as censuras da "mãe" relativas à lubricidade dos rapazes com as mulheres, a mocinha torna a se reunir com o atendente, num gabinete repleto de aves empalhadas. Lá, Marion aceita o sanduíche, o que representa uma "abertura" concedida a Norman. A conversa entre eles, um dos pontos altos do filme, detém uma carga erótica indisfarçável, e a reiteração do apego do rapaz pela sua mãe ("O melhor amigo de um garoto é sempre sua mãe") se interpola com seu mal disfarçado interesse sexual pela hóspede. Neste diálogo, a fala de cada personagem exprime sua inquietação peculiar frente à vida, e ao tempo. Marion teme perder a chance de ser feliz com Sam, e rouba o dinheiro do patrão no anseio da relação sexual bem sucedida, sem considerar que jogava fora sua boa reputação por 10 anos de serviços. Norman, por outro lado, recusa a todo preço a passagem do tempo, quer manter-se em sua ilha de gozo pulsional. Durante a conversa, no entanto, ele não se diz em situação inferior à dela, que considera presa numa armadilha também.

Segunda parte. A introdução de Norman como novo protagonista impõe uma mudança formal importante do ponto de vista da narrativa, e que caracteriza a "psicose" que dá nome ao filme. Para Zizek, esse corte é dado pelas facadas desferidas sobre Marion nua e indefesa no chuveiro, cuja violência parece afetar a própria montagem. É um momento de grande impacto, quando a perspectiva sob a qual a estória é contada se desloca. Dáse aqui uma espécie de "subversão" do olhar do espectador, que se vê desde então forçado a abandonar a identificação primeira com Marion. A partir daí, não estamos mais no campo do desejo e do objeto faltoso, mas sob o domínio das pulsões cegas e repetitivas, onde o objeto comparece como excesso cadavérico, sejam os pássaros empalhados, ou os olhos vidrados (alegoria do oco da subjetividade) da morta com a cara colada no chão do banheiro. A "temporalidade" da pulsão é a de um tempo fora do tempo, sem passagem nem perda, o tempo dos velhos hábitos, da lentidão rural, versus o tempo veloz da cidade e do dinheiro. Trata-se, no caso da psicose, de uma repetição 
ateleológica, como a do puro ato de sugar. O sujeito "partiu", "quebrou", não está "dividido" ou "inseguro" como no desejo, mas salta de uma identidade rígida para outra, sempre se eximindo da culpa, a qual implica uma divisão. Zizek avalia que, por não se apresentar como "faltoso" ou "desejante", é impossível nos identificarmos com Norman.

O desejo é um movimento metonímico ao infinito, um deslizamento para o objeto-causa originariamente perdido. Sempre insatisfeito, ele se presta a todas as interpretações, ele coincide mesmo com sua interpretação, ele é propriamente a passagem de um significante a outro, a incessante produção de novos significantes que dão seu sentido aos precedentes. A pulsão, ao contrário, é num sentido sempre já satisfeita. Limitada ao circuito fechado, a sua pulsação, em lugar de buscar um "sempre outro", ela gira em torno do objeto e acha seu gozo na pulsação mesma. Nisso, ela é parte integrante do real - ela é o que "volta sempre no mesmo lugar" (Lacan) -, enquanto o desejo está inteiramente no simbólico. Desde então apreende-se por que toda a identificação com a pulsão é proibida uma vez que ela é do registro do real, e o "real é o impossível". Só é possível a identificação com um outro enquanto sujeito desejante. Norman (protagonista de Psicose) enquanto sujeito psicótico prisioneiro de suas pulsões, fracassa na identificação - ele não tem acesso ao registro do desejo, que supõe a passagem pela lei paterna. $^{2}$

De forma automática, Norman limpa em silêncio o sangue do banheiro e mergulha o carro no pântano, com os 40 mil dólares (o que acentua o caráter "desinteressado" do crime). O carro trava antes de afundar totalmente, e nós, espectadores, sentimos um estranho alívio quando este desaparece de vez no pântano.

A terceira parte do filme, enfim, consiste na sequência posterior ao afundamento do carro até o desenlace da estória, com a revelação da autoria do crime, isto é, do agente por detrás da voz. Nesse momento se concentra a parte "analítica" do filme. Existem três formas de interpretação do assassinato apresentadas: a imaginária do senso comum, que supõe, de forma especular, que todos estão atrás do que "todo mundo" em geral está, isto é, do dinheiro. Outra idéia aludida, de efeito humorístico, é a de que Norman seria um travesti.

Cabem aqui duas considerações relativas a duas aparições nessa parte do filme. A primeira é a do detetive particular Arbogast. Para Zizek, por ser aguardada, sua morte na queda "inverossímil" da escada, seguida das facadas brutais, encena a distância, elaborada por Freud, entre saber e crença. Quando Arbogast se aproxima da casa, como se ela estivesse já a encará-lo com dois iluminados olhos/janelas, já sabemos que algo ocorrerá, e quando ocorre ainda assim nos surpreendemos, o que mostra que a forma do saber é distinta da crença inconsciente. A outra curiosa aparição é a do delegado de polícia da cidadezinha, casado, preguiçoso, com roupão de dormir, e que surge como uma segunda versão do pai, oposta ao patrão endinheirado de Marion: trata-se do pai impotente. É notável que a figura do pai, em Psicose, apareça sempre, por assim dizer, 'refratada', ora como o dono da firma bêbado, pai gozador de Totem e tabu, com poder demais e até semi incestuoso, ora como o delegado impotente da cidadezinha, para não falar do pai morto e do padrasto de Norman, morto por ele juntamente com a mãe, que 
no filme são apenas aludidos pelo psiquiatra. Tudo se passa como se a figura paterna só aparecesse por refração, como se a lei não existisse nela mesma, como se sua consistência não derivasse de uma propriedade que lhe fosse intrínseca, sendo sempre apreendida por um viés distorcido.

A segunda forma de interpretação introduzida por Hitchcock, não sem alguma hesitação (vide o making-off do filme), é a do psiquiatra como "mestre da significação", que lançando mão de seu saber explica didaticamente o caso através da hipótese (simbólica) da personalidade duplicada pela culpa. A função da sua fala de psiquiatra/cientista é a de por os pingos nos is, propondo uma visão objetiva do acontecido, esclarecendo a todos que o crime fora cometido por paixão, não por dinheiro.

A terceira hipótese se expressa no extremo fim, nos últimos dois segundos do filme, quando "Normãe" nos interpela com um enigmático sorriso de caveira. Isso, depois de afirmar ser incapaz de matar uma mosca, mini alegoria que alude ainda aos pássaros empalhados/mãe. Para Hitchcock, os pássaros encenam a libido materna, já que a mãe vem do alto sobre o bebê, tese que será retomada em Os pássaros. Este sorriso cadavérico se constitui, no nosso entender, como o momento da "Clínica do real", de Lacan $^{3}$, onde se põe a nu o vínculo de gozo entre nós, espectadores, e o facínora. Esta última naálise, dirigida não tanto ao assassino como a nós, espectadores, é prenunciada pela cena do "afundamento" do carro, na metade do filme. Quando ele deixa um instante de afundar, ficamos em suspense com Norman, que o observa apreensivo, e nos sentimos de algum modo aliviados quando o veículo prossegue afundando, levando o cadáver de Marion, sua mala, e os 40 mil dólares. Isso mostra que nós já compartilhávamos, de algum modo, da perspectiva do criminoso. Mas de que ponto de vista? Não da identificação com ele enquanto sujeito de desejo, mas com a modalidade (destrutiva) de seu gozo. Nessa medida, o olhar final da caveira tem menos por função dar um sentido ao que não tem sentido (visão tradicional da interpretação) do que apontar para o nexo de gozo sem-sentido (real) entre o analisando e seu sintoma.

\section{Articulações zizekianas entre desejo e pulsão}

Opostamente ao que ele mesmo afirma no Guia perverso do cinema, Zizek censura em seu texto sobre Psicose a leitura "simbolista" que veria no sótão da casa o símbolo do supereu, e o porão como simbolizando o isso, por exemplo. Esta leitura psicanalítica tradicional pretende ultrapassar o nível da aparência e apontar para um significado oculto, quando o supereu está desde sempre presentificado, formalmente, na voz acusmática da mãe (voz desprendida de seu corpo) ou no olhar da câmera, quando perde sua neutralidade e nos interpela num ar ameaçador. 
Apesar da distinção entre os dois registros, o do desejo e o da pulsão, o filósofopsicanalista esloveno considera tentador pensar que o cotidiano idílico e naturalizado de Marion (com sua irmã, seu namorado, etc) e o mundo noturno de Norman estabelecem uma estranha continuidade entre si, como se se tratasse ao longo do filme do reviramento do desejo em pulsão relativo a um mesmo personagem, como o próprio anagrama Marion-Norman o sugere.

A relação dos dois registros não é mais a de uma superfície calma e de uma profundidade tempestuosa, mas como as duas superfícies de uma tira de Mœbius: ao percorrermos um lado, subitamente nos encontramos sobre o outro. E o ponto de passagem entre as duas é o assassinato de Marion. ${ }^{4}$

Essa articulação entre pulsão e desejo se acha presente igualmente no primeiro capítulo de Looking awry, onde Zizek caracteriza a diferença entre o que seria o propósito [aim] e a meta [goal] da pulsão. Ele analisa isso tomando de empréstimo o mito de Sísifo, condenado a empurrar uma pedra até o topo de um monte, por toda a eternidade. Enquanto a META da pulsão é colocar a pedra no alto, de forma sempre hesitante, do ponto de vista de seu PROPÓSITO (no caso, a reiteração do ato de empurrar pedras, tomado em si mesmo) a pulsão é sempre exitosa. Em outras palavras, trata-se da diferença entre "não consegue" e "consegue não" realizar a tarefa.

Para Lacan, a visada real da pulsão não é sua meta (a plena satisfação) mas seu propósito: o propósito último da pulsão é simplesmente reproduzir a si mesmo como pulsão, retornar a sua via circular, continuar sua via para e a partir da meta. A real fonte de gozo é o movimento repetitivo desse circuito fechado. ${ }^{5}$

O Desejo nasce da interdição, esse é um ponto central da psicanálise. A lei ${ }^{6}$ não reprime um impulso supostamente natural, mas arranca o homem da continuidade com a natureza, remetendo a causa mais fundamental de suas motivações a um objeto faltoso, supostamente desejado pelo Outro. Pois a lei, fundamentalmente, é aquela que interdita ANTES o gozo do Outro que o do sujeito. Este último é dividido, neurótico, busca a relação sexual impossível, e se vê culpado por infringir a lei. Esta lei advém no lugar do Outro como voz ou olhar de autoridade (Outro como Ideal do eu), que mal disfarça, como que em contraface, um gozo sádico sem sentido (Outro como Supereu). Esta dupla possibilidade é alegorizada pelo guarda de óculos escuros, dessubjetivado, e retornará de forma cruel e gozoza na VOZ da "mãe", despregada do corpo.

A Pulsão, como entidade pré-simbólica, está desde sempre satisfeita. Limitada ao circuito fechado de sua própria pulsação, ela acha aí sua plena satisfação, seu gozo inercial, alegorizado pelos pássaros empalhados em sua ambiguidade de mortos-vivos. Ela é "parte integrante do real", o que "retorna sempre no mesmo lugar" (enquanto o desejo se acha inteiramente no simbólico). A pulsão é inércia temporal, vínculo viscoso à "Coisa Materna", recusa da subjetivação da falta. Assim, Norman "salta" de uma 
personalidade para outra, mas não se experimenta como dividido, ou desejante: nos termos de Lacan, ele foracluiu o nome/não do pai [non-du-père].

Na psicose, o OLHAR como objeto comparece na janela acesa da casa, e na VOZ incorpórea do superego materno, percebe-se uma dimensão de obscenidade gozosa. Ao descer a mãe para o porão, ela ou sua voz diz: você pensa que eu sou "desfrutável" [fruity ${ }^{7}$. No documentário Guia perverso do cinema, Zizek interpreta esse momento como ilustrando uma tese de Freud em $O$ ego e o id, a de que há uma conexão íntima entre o supereu e o isso. Ou seja, de que a própria lei se alimenta da energia tomada das pulsões, que é reputada refrear.

Por fim, numa de suas considerações mais interessantes acerca de Psicose de Hitchcock, Zizek caracteriza este filme como uma crítica possível ao Anti-Édipo de Deleuze e Guattari:

Norman Bates seria um Anti-Édipo avant la lettre; para chegar a se liberar do supereu materno, para se arrancar a essa figura cruel e arbitrária do Outro, falta-lhe a Lei capaz de frear o desejo - não o seu desejo mas o desejo do Outro, da mãe. Antes da intervenção da Lei o sujeito é vítima dos caprichos do Outro, e isso 'introduz o fantasma da Onipotência não do sujeito, mas do Outro onde se instala sua demanda [...] e com esse fantasma a necessidade de freá-lo pela Lei' (Lacan, Escritos). Por esta razão, a intervenção da lei é uma 'desalienação', pois ela freia o desejo do Outro, o fantasma da Onipotência do Outro onde o desejo do sujeito é alienado, introduzindo uma regra à qual o próprio Outro deve obedecer.

Contudo, tal consideração não deve nos fazer pensar que a psicanálise conduz a um elogio da Lei paterna:

\begin{abstract}
Seria entretanto errôneo concluir do que precede que a psicanálise reivindica a Lei paterna. Ela não ignora que o pai legislador é um impostor, e que esta posição se sustenta somente por um Outro do Outro: o pai ocupa um lugar impossível, originariamente vazio, aquele da falta no Outro, do buraco em torno do qual se articula a ordem simbólica. Os partidários do Anti-Édipo, que afirmam o desejo contra a Lei paterna, desconhecem precisamente este dado incontornável. A verdadeira transgressão da Lei paterna não consiste em liberar o desejo dos entraves postos pela lei, mas antes em fazer a experiência deste vazio, desse buraco no Outro onde se aloja a impostura do pai, o que implica admitir o caráter 'não-todo' do Outro. A verdade que tenta dissimular essa impostura é esse buraco, e a ofuscante figura paterna não oculta nada de outro que o vazio de seu lugar. É por isso que a ilusão dessa impostura é consubstancial à verdade: não há verdade sem engano, como não há lugar vazio sem o elemento de que esse lugar é o lugar. ${ }^{8}$
\end{abstract}

Para Zizek, há uma impossibilidade de identificação com Norman, na medida em que só nos identificamos com um sujeito faltoso. A identificação primordial é, portanto, fundamentalmente, com a falta no Outro e/ou Lei paterna. É exatamente a subjetivação dessa falta que falta ao psicótico. Ele não suporta não ser o objeto totalizante que 
preenche o vazio do Outro, impedido assim de desejar. Desde então, assassinatos serão cometidos em nome do zelo filial.

\section{Conclusão}

Levando em conta a distinção entre Desejo e Pulsão, as três partes do filme ficam, desde então, assim caracterizadas:

\section{Dialética do desejo (Estrutura Neurótica - uma divisão)}

Do início do filme até o assassinato de Marion. Estamos em plena ordem fálica: a pulsão sexual escópica do espectador se conecta com a falta no Outro, primeiramente através do "olhar da câmera" pela janela do hotel. Depois, pela bolsa cheia de dinheiro (40 mil dólares!) que promoveria para a protagonista, com a qual de asída nos identificamos, a relação sexual, a conquista do amor do Outro.

\section{Repetição pulsional (Estrutura Psicótica - duas personalidades).}

Logo após as facadas - penetração "over" que denuncia a impotência sexual de Norman - temos a silenciosa lavagem do banheiro até o afundamento do carro no pântano, após um pequeno suspense.

\section{Três formas de interpretação}

$\mathrm{Na}$ terceira e última parte assistimos ao desvendamento do crime, com seus respectivos procedimentos analíticos de "interpretação". Existem, a meu ver, três hipóteses diferentes levantadas: primeiro, a suposição imaginária ou "projetiva" de senso comum, de que o sumiço fora motivado por interesse financeiro. Hipótese geral, de fato, mais facilmente inteligível. Segunda tese, a do analista/psiquiatra como mestre da significação: fora um crime de paixão. O personagem, nesse caso, porta o discurso "objetivo", científico, neutro, acerca do que realmente ocorreu. Ele elucida a "lógica interna" dos assassinatos a partir da formulação da hipótese/diagnóstico da "dupla personalidade" de Norman. A terceira e última forma de interpretação consiste na interpelação do espectador pelo sorriso sarcástico da caveira putrefata, revelando seu vínculo com o facínora numa dimensão de gozo por ele próprio ignorado. É como se este horrendo sorriso à la cantonade dissesse: "Não é doce poder trucidar, penetrando-o a facadas, nosso mais querido objeto de desejo?" 
${ }^{1}$ ZIZEK, S. (org.) Tout ce que vous avez toujours voulu savoir sur Lacan sans jamais oser le demander à Hitchcock. Paris: Navarin, 1988, p. 182.

${ }^{2}$ ZIZEK, S. Op. cit., p. 187.

${ }^{3} \mathrm{~A}$ análise consiste em dar sentido ao que não tem sentido aparente ou perceber um fundo de não sentido gozado no fundamento mesmo do sentido? Situa-se aí, ao que parece, a distância entre Freud e Lacan.

${ }^{4}$ ZIZEK, S. Op. cit., p. 182.

${ }^{5}$ ZIZEK, S. Looking awry: An introduction to Jacques Lacan through popular culture. London: MIT press, 1992, p. 5.

6 Para Lévi-Strauss, em As estruturas elementares do parentesco, a interdição do incesto é necessária, embora não seja natural, e convencional, embora não seja contingente. Na verdade, ela se situa numa espécie de "meio caminho" entre a natureza e a cultura.

${ }^{7}$ Fruity em inglês quer dizer: relativo à fruta, que cheira à fruta; escabroso, com um sabor de escândalo.

${ }^{8}$ ZIZEK, S. (org.) Tout ce que vous avez toujours voulu savoir sur Lacan sans jamais oser le demander à Hitchcock. Op. cit., pp. 188-189. 